\title{
Skull base chordomas: overview of disease, management options, and outcome
}

\author{
Giuseppe Lanzino, M.D., Aaron S. Dumont, M.D., M. Beatriz S. Lopes, M.D., \\ AND EDWARD R. LAWS, JR., M.D. \\ Department of Neurosurgery and Division of Neuropathology, University of Virginia Health Sciences \\ Center, Charlottesville, Virginia
}

\begin{abstract}
Cranial base chordomas are locally invasive tumors that, from a midline, clival location, extend in different directions and display various patterns of skull base invasion. Although histologically benign, their invasive nature makes true "oncological" resection virtually impossible to achieve in most cases, despite modern skull base surgical techniques. Moreover, because of the tumor's location and proximity to critical neural and vascular structures, surgeryrelated morbidity can be significant when an aggressive resection is undertaken. Cytoreductive surgery assumes a critical role in the management of these lesions. The choice of surgical approach and the extent of resection are dependent on several factors: location and extension of the tumor, the surgeon's philosophy and familiarity with a specific approach, and the patient's preexisting clinical status. Proton-beam radiotherapy seems to be effective as an adjunct to surgery in achieving local tumor control. The timing of radiation therapy, however, remains controversial. Gamma knife surgery has been proposed as an adjunctive therapy, but the limited experience and short follow-up periods do not permit formulation of meaningful conclusions at this time. Recurrences are common, although in a subset of patients prolonged disease-free survival is demonstrated.
\end{abstract}

\section{KEY WORDS • chordomas • skull base tumor • proton • radiation therapy • gamma knife}

Chordomas comprise a group of locally invasive extraaxial neoplasms that originate from notochordal remnants. Notochord remnants can occur anywhere along the axial skeleton, although they are much more common at either the upper (clivus) or lower (sacrum and coccyx) end. Consequently, chordomas are most frequently encountered in the sacrum (approximately 50\%) or the clivus (35\%). ${ }^{41,73,101}$

Intracranial chordomas almost invariably involve the clivus. ${ }^{32,55,56}$ Within the clivus, the notochord has a sinuous course, thus explaining the diverse origin and projections of cranial base chordomas. ${ }^{56}$ Chordomas arising from the most rostral notochord extension in the dorsum sellae present as sellar ${ }^{96}$ or parasellar tumors. Those arising from the most ventral aspect of the clivus can present as nasopharyngeal chordomas, ${ }^{16,42,75,80,108}$ whereas those associated with the body and dorsal aspect of the clivus manifest as sphenooccipital or petrosal lesions. Chordomas related to the lower clivus will present at the ventral portion of the foramen magnum. ${ }^{56}$ Lateral growth of these neoplasms from their midline origin frequently results in invasion of the cavernous sinus, which can be demonstrated radiologically in 54 to $75 \%$ of cases. ${ }^{1,35}$ Cavernous sinus invasion probably occurs as the tumor follows the course of the sixth cranial nerve rather than through direct dural invasion. ${ }^{9}$ Direct dural invasion, however, is the most likely pattern responsible for extension into the posterior fossa. ${ }^{9}$

Cranial base chordomas have been reported in all age groups, including children and adolescents. ${ }^{10,20,49,59,71,90,106}$ In large series, the median age at diagnosis is 46 years. ${ }^{32}$

Abbreviation used in this paper: $\mathrm{MR}=$ magnetic resonance.
Diplopia is the most commonly reported symptom at pre-

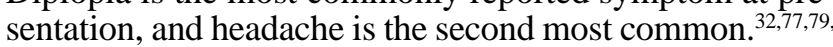
100,104 Of all the cranial nerves, the sixth is the most likely to be involved by the lesion at presentation. ${ }^{19,32,100}$ Because of the slow-growing nature of the mass, it was not uncommon in the pre-computerized tomography and pre-MR imaging era for the tumor to go undiagnosed for a long period of time. ${ }^{19}$

\section{OVERVIEW OF SKULL BASE CHORDOMAS}

Chordomas are locally invasive extraaxial lesions (Fig. 1) that begin with expansive destruction of bone at the site of origin; this is followed by subsequent infiltration and transgression of the dura, eventual widespread intracranial extension, and encasement of cranial nerves, brainstem and vascular structures. Although rare, primarily intradural intracranial chordomas have been encountered. ${ }^{70,107}$ Metastatic dissemination is possible and becomes clinically manifest in 10 to $20 \%$ of the patients. ${ }^{54}$ At autopsy, however, foci of metastatic disease can be found in up to $40 \%$ of patients. ${ }^{54}$

Macroscopically, chordomas are soft, gelatinous, lobulated neoplasms. The extraosseous portion tends to have a pseudocapsule with some separation from the surrounding neural structures. ${ }^{9}$ Clinically and radiologically, ${ }^{97}$ chordomas can usually be readily differentiated from benign, asymptomatic, nonneoplastic notochord remnants, also known as ecchordosis physaliphora. These lesions are not uncommon and are found in approximately $2 \%$ of autopsy material. ${ }^{14}$

Microscopically, the tumor cells are arranged in lobules 


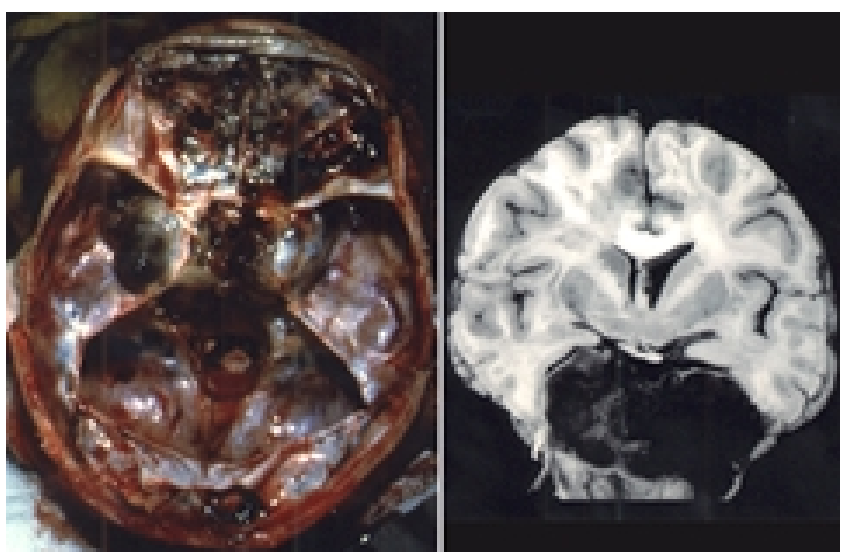

Fig. 1. Left: Photograph showing a gross autopsy specimen of a large chordoma with diffuse erosion of the clivus and lateral extension of the mass involving both cavernous sinuses and the middle fossa bilaterally. Right: Gross autopsy specimen in a patient with large chordoma extending in the sella, suprasellar, and parasellar areas.

delimited by fibrovascular septae. The lobules comprise rows or cords of phenotypically epithelial cells-small polygonal cells with eosinophilic cytoplasm and eccentric nuclei-in a mucoid matrix (Fig. 2 upper left). The most typical feature of the tumor cells is the presence of vacuolated, bubble-containing cytoplasm characterizing the so-called physaliphorous cells (Fig. 2 upper right and lower left). These cells correspond to the basic histological architecture of the notochord. ${ }^{15}$ The invasive nature of these tumors is evidenced by the fact that islands of tu- mor cells can be found completely surrounded by normal-appearing bone. ${ }^{41}$ In some cases, malignant foci with pleomorphism and mitotic figures are observed. Malignant degeneration into patterns such as malignant fibrous histiocytoma, undifferentiated spindle cell tumor, ${ }^{98,101}$ or chondrosarcoma can occur over time. ${ }^{15}$

The differentiation of chordomas from cartilaginous tumors such as chondromas and chondrosarcomas on a histological basis alone can be difficult. ${ }^{81}$ In such cases, immunohistochemistry can be helpful. Chordomas express epithelial markers including cytokeratin ${ }^{63,78}$ (Fig. 2 lower right) and the epithelial membrane antigen. ${ }^{63,67}$ Chondrosarcomas, which are neoplasms of mesodermal origin, fail to react with such epithelial antibodies. ${ }^{14}$ With the use of modern immunohistochemistry, up to $20 \%$ of neoplasms previously classified as "histologically verified chordomas" were indeed found to be chondrosarcomas. ${ }^{104}$

Considerable confusion has arisen since Heffelfinger, et al., ${ }^{41}$ asserted in 1973 that chordomas with prominent chondroid features (the so-called chondroid chordoma) might have a more favorable prognosis. In a recent clinicopathological study, however, the authors found no difference in the survival of patients with such chordomas compared with conventional chordomas and chondrosarcomas. ${ }^{68}$ Instead, the more favorable prognosis in patients with chondroid chordoma was attributed to the tumor's occurrence in younger patients. ${ }^{68}$ At present, the controversy regarding the significance and true nature of chondroid chordomas remains unresolved. ${ }^{12-14,63,66,99,103,105}$

\section{IMAGING CHARACTERISTICS}

Thin-cut computerized tomography scans obtained

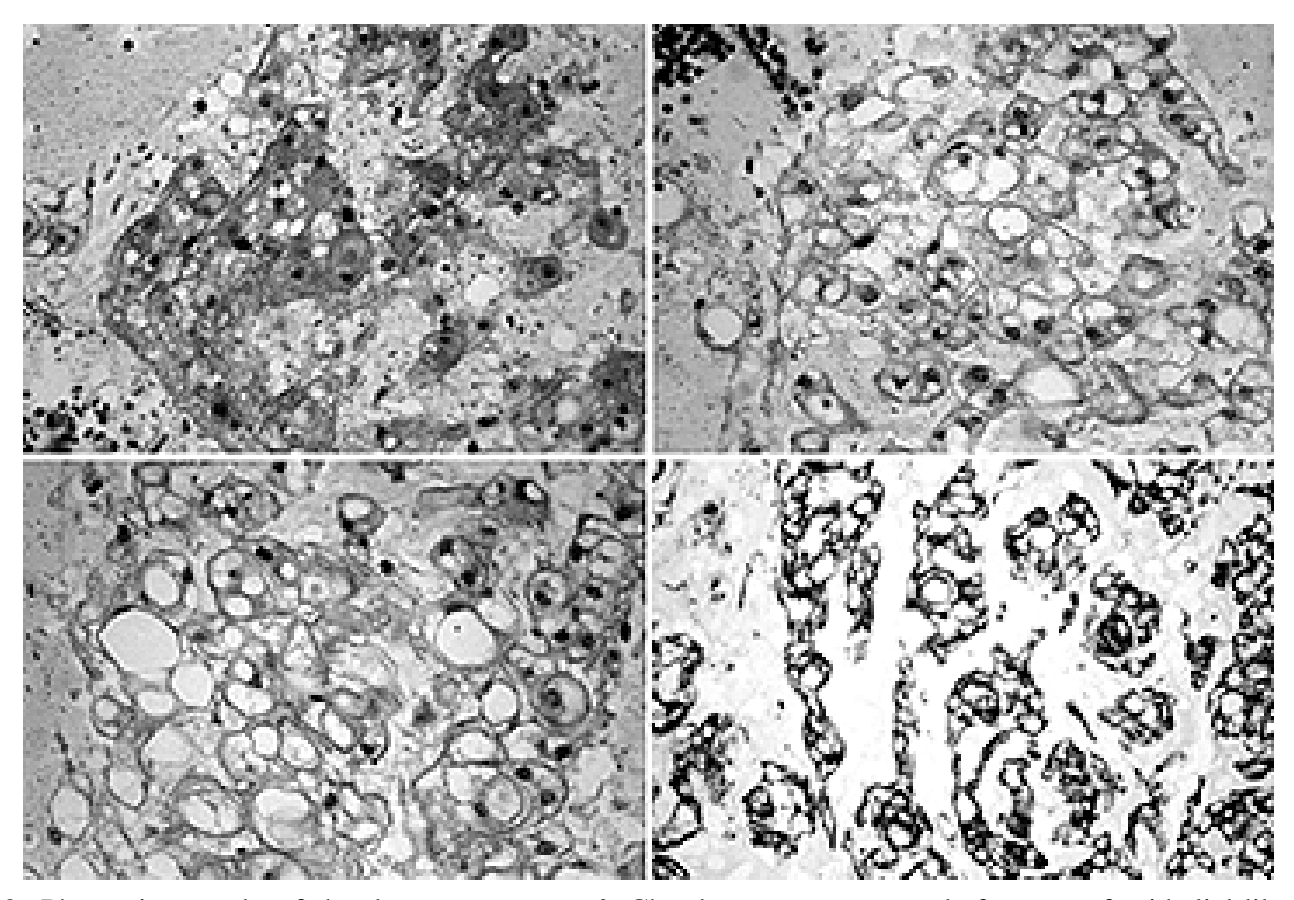

Fig. 2. Photomicrographs of chordoma. Upper Left: Chordomas are composed of groups of epithelial-like cells immersed in a mucinous matrix. Upper Right and Lower Left: Physaliphorous cells with vacuolated, bubble-bearing cytoplasm are the hallmark of these neoplasms. Lower Right: Immunohistochemistry for cytokeratin delineates islands of tumor cells within the mucoid matrix. H \& E; original magnification $\times 300$. 


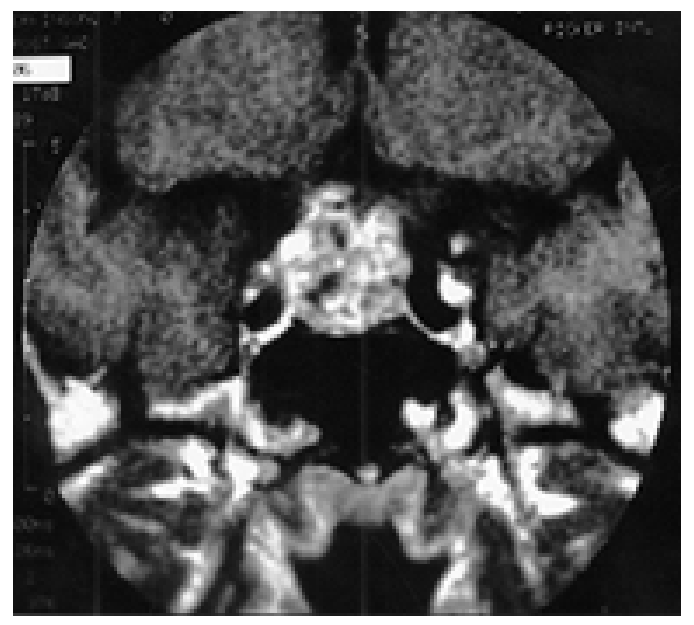

Fig. 3. Coronal gadolinium-enhanced MR image demonstrating the characteristic heterogeneous pattern of enhancement. Magnetic resonance imaging allows excellent characterization of the relationship between the tumor and the carotid artery.

through the skull base are ideal for evaluating the degree of bone invasion and extension. ${ }^{53}$ Chordomas typically cause osteolytic bone changes without evidence of surrounding sclerosis. ${ }^{46,53,65}$ Gadolinium-enhanced MR imaging will more clearly define the extent of the disease. ${ }^{28,53,65}$ On $\mathrm{T}_{1}$-weighted MR imaging, chordomas generally demonstrate a low to moderate signal intensity. ${ }^{65}$ In some cases, scattered small areas of increased signal intensity on $\mathrm{T}_{1}$-weighted images can be seen. ${ }^{65}$ These areas may represent small foci of hemorrhage. ${ }^{65}$ Almost uniformly, they appear hyperintense on $\mathrm{T}_{2}$-weighted MR imaging studies, which most likely reflects the high fluid content of the vacuolated cellular components. Overall, nearly all chordomas demonstrate some degree of enhancement. Gadolinium enhancement is mostly heterogeneous $(81 \%$ of cases) (Fig. 3). ${ }^{65}$

\section{SURGICAL STRATEGY: RADICAL OR CONSERVATIVE RESECTION}

In 1909 Harvey Cushing was likely the first surgeon to remove a chordoma successfully. ${ }^{24}$ The patient, a 35 -yearold man, presented with headache, progressive visual loss, left oculomotor palsy, and hypopituitarism (Fig. 4 left). This tumor was initially mistakenly reported as a teratoma (Case XVII) in his monograph, The Pituitary Body and its Disorders. Following surgery, the patient experienced transient symptomatic improvement. Six months later he was readmitted for worsening headache and underwent reoperation. Unfortunately, he died in the immediate postoperative period of causes related to intraventricular hemorrhage. At autopsy, Cushing wrote, “.... large friable tumor mass..." was found (Fig. 4 right). Cushing went on, "The growth is of spherical type, roughly $5 \mathrm{~cm}$ in diameter. It clearly has not originated from the hypophysis itself, for the flattened remnants of the gland are found by tracing down the anteriorly displaced and greatly elongated infundibulum and stalk." Histologically, the tumor consisted of "...embryonic cartilage containing a few bone cells with myxomatous and connective tissue." William

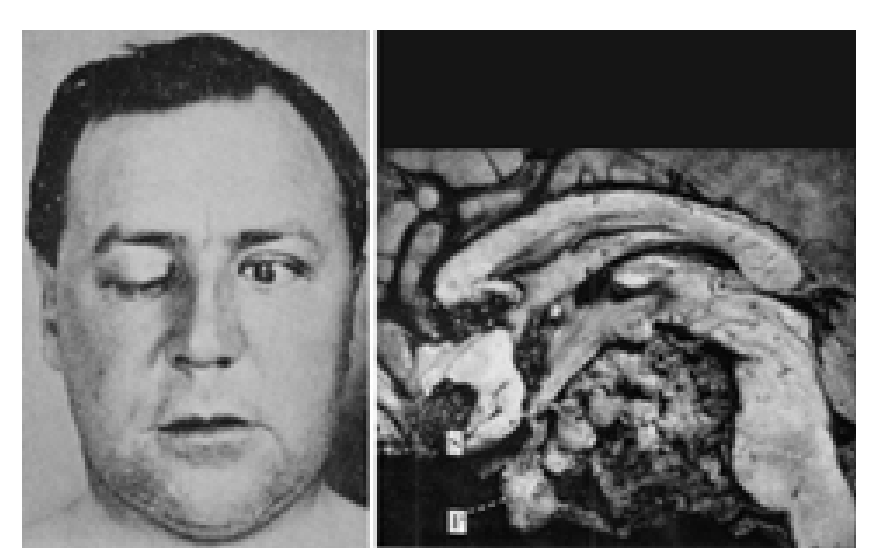

Fig. 4. In 1909 Harvey Cushing was likely the first surgeon to resect successfully a chordoma. Left: The patient pictured here, a 35 -year-old man, presented with headache, progressive visual loss, left oculomotor palsy and hypopituitarism. The patient died after repeated surgery. Right: In describing the autopsy specimen Cushing observed, "It clearly has not originated from the hypophysis itself, for the flattened remnants of the gland are found by tracing down the anteriorly displaced and greatly elongated infundibulum and stalk."

Welch, the famous pathologist, described the lesion as a "mixed tumor from a congenital anlage." In a later review of the tissue diagnosis, Bailey and Bagdasar ${ }^{6}$ were able to correctly recognize the histological features as those typical of chordoma.

Commenting on this case, Cushing recognized that radical excision would have been impossible and wisely concluded:

Could one have known what was amiss with this patient and had surgical measures reached a stage of development which rendered intervention permissible, the proper treatment would have been (1) to have removed the sellar base on the first indication of neighborhood symptoms (cf. Case XX), thus saving vision and relieving the hypophysis from the superimposed pressure, and (2) to have removed the benign lesion, whether by a transsphenoidal or subtemporal route, in fragmentary fashion whenever an increase in symptoms showed that the optic nerves were again becoming implicated. There is every reason to suppose that a working life might thus have been spared in comfort for many years.

Almost a century later, Harvey Cushing's conclusive words sound remarkably pertinent.

In the late 1980s and early 1990s, fostered by technical advances in skull base surgery, an aggressive surgical approach to cranial base chordomas has been proposed., ${ }^{1,3}$, 35,52,83 The impetus for such an aggressive approach stemmed from the observation that, at least in the case of sacral chordomas, long-term survival and even cure can be achieved with radical removal of the tumor as well as a clear margin of surrounding bone. In the past few years, however, this initial enthusiasm has been tempered by the realization that, notwithstanding technical advances, a true oncological resection of these cranial base tumors can hardly, if ever, be achieved. Removal of the tumor with a clear margin of tissue is virtually impossible in the clivus. ${ }^{21}$ Moreover, aggressive tumor resection is accompanied by a substantial procedure-related complication rate. ${ }^{35}$ Because of the slow growth of many chordomas, it is now being increasingly recognized that, as Cushing elo- 
quently expressed, "... a working life..." can be "spared in comfort for many years" by different combinations of judicious resection and high-energy radiation therapy.

Interpretation of published data on the survival and disease-free interval is difficult because of the small number of patients, short follow-up periods, and the tendency not to differentiate between patients with cranial base chordomas and those with chondrosarcomas. Analysis of the few series in which there was sufficient follow-up time to support meaningful conclusions seems to suggest the existence of two separate groups of patients with distinct survival patterns: one with a very high mortality rate within the first 3 to 5 years and the other with a much more indolent disease process and, in some cases, almost normal life expectancy. $7,32,43,95,104$ Collectively, this suggests that the biological course of the tumor can be variable and, like other skull base tumors, may be a primary determinant of eventual patient outcome. Indeed, very early recurrences only a few weeks following radical surgery have been observed in lesions displaying pathological features consistent with typical chordoma without findings of atypia. ${ }^{1}$ In contrast, long-term survival has been reported in patients who have undergone partial tumor resection but not radiotherapy. ${ }^{79,102}$

At present, there is no convincing evidence that the availability of modern aggressive surgical approaches coupled with advances in preoperative neuroimaging has resulted in improved prognosis for patients with skull base chordomas. ${ }^{104}$ There is no question, however, of the value of resection in establishing a pathological diagnosis, alleviating symptoms, and reducing tumor bulk, thereby delaying future recurrences. It also possible that surgical cure can be achieved in the rare case of a chordoma confined to a single area of the skull base. A more conservative approach consisting of observation alone or biopsy sampling followed by radiotherapy is indicated in older patients or in those with significant comorbidities for whom a more extensive surgery poses a high risk.

In our opinion, safe, cytoreductive resection in which the goal is to remove as much of the tumor as possible while minimizing complications seems currently to represent the best surgical strategy. Removal of bone margins surrounding the tumor should be performed whenever safely feasible. Chordomas are often soft, easily "suckable," and, unlike other neoplasms such as meningiomas, often do not require extensive dissection from the involved cranial nerves and vascular structures. ${ }^{38}$ Despite these characteristics, in cases with frank cavernous sinus involvement, aggressive resection should not be considered in patients with normal preoperative extraocular motility function because of the surgery-related morbidity associated with this location. This is particularly true in patients who have undergone previous surgery and/or radiotherapy, both of which appear to increase the surgeryrelated morbidity associated with these lesions. ${ }^{35,52}$ When brainstem involvement is present, decompression of this critical structure is of paramount importance. Brainstem compression is not only an important component critically affecting survival but is also a major factor limiting the effectiveness of high-energy radiotherapy.,43 Some authors have even advocated the use of autologous fat graft as a spacer to increase the distance between the involved clivus and the contiguous brainstem to facilitate safe delivery of high-dose radiotherapy. ${ }^{22}$

\section{SURGICAL APPROACHES}

Several factors including tumor location, the surgeon's familiarity with the surgical approach and his/her philosophy, the extent and pattern of tumor invasion, the patient's preoperative clinical status, and history of previous surgery and/or radiotherapy have to be taken into account when choosing how to approach the lesion. Based on these factors, the surgical approach can be tailored to the specific situation of the individual patient.

A classification scheme, proposed by Al-Mefty and Borba, ${ }^{1}$ can be helpful in formulating a surgical plan. Type I chordomas are those strictly confined to one compartment of the skull base (defined as a solitary anatomical area such as the sphenoid sinus, cavernous sinus, or lower clivus); these lesions are infrequently encountered. Type II chordomas are those that extend to two or more contiguous areas of the cranial base and whose radical removal can be achieved using a single skull base approach. Type III chordomas represent those that extend to several contiguous compartments and whose radical resection requires two or more skull base procedures.

Usually chordomas arise as extradural tumors, but they can invade the dura in their advanced stages. Because intradural involvement and subsequent spread with varying degrees of involvement of intraarachnoid structures can occur as a result of previous surgery, the initial approach to these tumors should be extradural whenever possible. ${ }^{88}$ An extradural approach also provides ready access to the area of involved bone, which should be extensively removed whenever feasible. Overall, the approaches used in removing cranial base chordomas can be schematically divided into anterior and lateral approaches. To achieve satisfactory tumor exposure, various combinations of the approaches are required in large-sized chordomas. A detailed analysis of the advantages and disadvantages of each approach proposed for resection of skull base chordomas is beyond the scope of this article, and excellent reports have already been published on this topic. ${ }^{1,11,17}$, 23,26,27,33,36,37,45,47,51,55,57,58,76,86-89,94

Careful study of the preoperative neuroradiological studies is essential when planning the surgical approach to these challenging lesions. In recent years, continuous refinements of frameless stereotactic systems have come to provide the surgeon with intraoperative feedback regarding surgical orientation. These systems have significant limits in cases of intraparenchymal or extraaxial nonbone-invading lesions because of structural shift, which occurs after dural opening and intraoperative drainage of cerebrospinal fluid. However, given the static nature of the bone structures, several authors have suggested that frameless stereotactic guidance can be helpful in the case of lesions such as chordomas that extensively invade the base of the skull. ${ }^{62,84}$ Indeed, in a number of situations we have found frameless stereotaxis to be helpful in providing intraoperative feedback regarding surgical orientation and, indirectly, extent of resection during anterior extradural approaches to cranial base lesions. ${ }^{29}$ With further technological advancements and continuing refinements intraoperative neuroimaging and guidance will likely assume a critical role during resection of such tumors.

\section{RADIATION THERAPY}

Although traditionally heralded as so-called radiore- 
sistant tumors, chordomas are being increasingly treated with radiotherapy in an attempt to gain local control of this tumor, which is prone to local recurrence. An evolving experience with radiotherapy has helped to shape our contemporary understanding of its role as an adjuvantive therapy in the treatment of chordomas; additionally, it has also highlighted areas that need to be rigorously addressed in future investigation. ${ }^{44,93}$

\section{Conventional Radiotherapy}

Conventional radiotherapy was first attempted to gain local control of skull base chordomas. As a consequence of early experience with conventional radiotherapy (doses of 45-60 Gy), chordomas were deemed radioresistant in light of the tumor recurrence apparent in most treated patients. Data have accrued and analysis indicates that conventional radiotherapy is associated with poor progression-free and overall survival rates, ${ }^{18}$ although modestly improved results have been demonstrated when using escalated doses. ${ }^{4,34,74}$ The fact that recurrence rates approaching 50 to $100 \%$ have been reported pursuant to conventional radiotherapy (with similarly poor local control and survival curves) ${ }^{43}$ has led to the examination of other forms of radiation therapy as an adjunctive treatment modality for skull base chordomas.

\section{Proton-Beam Radiotherapy}

Proton-beam radiotherapy perhaps represents the most promising adjunctive treatment for skull base chordomas and considerable experience with its use has been reported. Commendable investigations (continuing to be updated) performed by groups at the Loma Linda University Medical Center, ${ }^{43}$ the Massachusetts General Hospital/ Harvard Cyclotron Laboratory, ${ }^{5,7,82,92}$ and the Lawrence Berkeley International Laboratory ${ }^{8}$ have formed the basis of this experience. ${ }^{44}$ Proton irradiation offers improved dose localization capabilities compared with photon therapy. The positive charge of protons provides an energydependent finite range in tissues, and the energy deposition (or application of the radiation dose) demonstrates a sudden rise in dose at the end of the range with a subsequent sharp falloff to zero dose (known as the Bragg peak effect), thereby providing excellent dose localization. ${ }^{44}$ Proton-beam radiotherapy does not produce resolution of chordomas but provides local tumor control defined as no progression of tumor-attributed clinical symptoms or radiologically demonstrated size. ${ }^{4}$

Recently, Hug and colleagues ${ }^{43}$ have reported their experience with 58 patients harboring cranial base chordomas or chondrosarcomas. They reported 5-year actuarial survival rates of $100 \%$ and $79 \%$ for patients with chondrosarcomas and chordomas, respectively, with acceptable risks. ${ }^{43}$ Tumor recurrence after proton-beam radiotherapy often occurs in areas where the dose is limited by dose constraints of sensitive areas such as the brainstem, spinal cord, or optic apparatus. ${ }^{4}$ Recurrences along the surgical pathway are uncommon. ${ }^{30,31}$ Overall, it is apparent that fractionated proton-beam radiotherapy (particularly with three-dimensional planning) provides excellent outcome as an adjunctive treatment for skull base chordomas. Indeed, the combination of judicious resection followed by high-dose proton-beam radiotherapy appears to offer the greatest probability of tumor control and overall survival for patients with skull base chordomas. Further refinements of proton radiotherapy may improve upon this in the future.

\section{Radiosurgery and Interstitial Brachytherapy}

Radiosurgery as an adjunct in the treatment of skull base chordomas is currently in a stage of relative infancy (Fig. 5)..$^{25,48,69,91}$ Muthukumar and colleagues ${ }^{68}$ updated the group's previous experience ${ }^{48}$ and reported treatment of 15 patients with skull base chordomas and chondrosarcomas in whom ${ }^{60} \mathrm{Co}$ gamma knife surgery was performed. At a median follow-up period of 40 months, two patients had died of the disease, two had died of intercurrent disease, and one surviving patient had developed tumor progression at the time of analysis. ${ }^{68}$ The paucity of information presently available on examining the role of radiosurgery for treatment of chordoma prevents any conclusions from being formed at this time. It will be particularly important to perform further analysis of the role of radiosurgery as an adjunctive treatment modality and carefully scrutinize its efficacy in relation to the currently available fractionated proton radiotherapy, especially in tumors of comparable size and configuration amenable to radiosurgery.

Implantation of ${ }^{125} \mathrm{I}$ seeds in brachytherapy has been anecdotally reported as an adjunctive treatment in the management of skull base chordomas. ${ }^{39,50}$ Both Gutin, et al., ${ }^{39}$ and Kumar, et al., ${ }^{50}$ have separately demonstrated that ${ }^{125} \mathrm{I}$ interstitial brachytherapy can be used in skull base chordomas with partial success. Given the rarity of skull base chordomas and the relatively frequent use of other radiotherapeutic modalities in adjunctive treatment, it will take some time for meaningful data to emerge so that the efficacy of brachytherapy for chordomas can be judged.

The existing body of literature in which authors investigate the role of radiotherapy in the management of skull base chordomas is hampered by several limitations, and other important questions await definitive exploration. First, in many of the reported series the authors discuss chordoma and chondrosarcoma patients as a single group. It is now generally agreed that these tumors behave differently and patients with chordomas have a poorer prognosis and a poorer response to radiotherapy than those with chondrosarcoma. ${ }^{44,81}$ Furthermore, the fact that chordomas and chondrosarcomas are difficult to differentiate histologically (and, as mentioned earlier, reports indicate that histological diagnoses for some tumors have changed over time) further complicates the interpretation of data. Additionally, there is some controversy as to the optimum time frame for undertaking adjunctive radiotherapy in patients with skull base chordomas. Some authors have suggested that radiotherapy should be conducted immediately following resection ${ }^{1,2,9,30}$ or in cases with atypical lesions. ${ }^{64}$ Other authors have advocated observation for evidence of tumor recurrence. ${ }^{58,88} \mathrm{We}$ prefer to tailor our treatment to the individual case and reserve adjunctive radiotherapy for those patients in whom there is postoperative radiological evidence of disease or in cases in which a small recurrent tumor is amenable to focused radiotherapy (Fig. 5). We also believe that postoperative radiotherapy should be strongly considered in those cases of chordomas with histological findings of atypia, in which there 
are highly represented areas of necrosis and/or elevated proliferative indices.

The optimum radiation dose must also be unequivocally established for skull base chordomas to maximize tumor control while minimizing adverse effects. Prognostic factors predictive of successful and safe tumor control are also surfacing, although there is no complete agreement. Tumor size and radiation dose appear to be inverse and direct, respectively, predictors of tumor control..$^{5,43,72,95}$ Other factors such as sex (female sex being associated with a poorer prognosis), ${ }^{5,40,72}$ involvement of dose-limiting structures, patient age, primary compared with recurrent disease,$^{30}$ and pathological features are also currently being studied. Prognostic factors, once firmly established, may assist the clinician in formulating therapeutic decisions.

There is no evidence at this stage that chemotherapy has any role in the treatment of patients with intracranial chordomas, although temporary response has been reported in isolated cases. ${ }^{85}$

\section{PATIENT OUTCOME}

Outcome after diagnosis of cranial base chordomas varies greatly, and as previously mentioned, is primarily related to the intrinsic biological behavior of the tumor. Forsyth and coworkers ${ }^{32}$ have analyzed the Mayo Clinic experience with 51 patients treated until 1984. The main strength of their study is the length and completeness of their follow-up analysis. Thirty-four patients $(67 \%)$ had died at the time of their analysis, and all but three deaths were related to the original tumor. ${ }^{32}$ Follow-up periods in which the 17 living patients underwent neuroimaging studies ranged from 5.6 to 29.7 years (median 8.3 years). The estimated total survival rates were $51 \%$ and $35 \%$ at 5 years and 10 years, respectively, and these were significantly different from expected survival rates for an agematched population. Only $24 \%$ of the patients were disease-free (alive without clinical progression). ${ }^{32}$

As alluded to previously, in several studies the authors have tried to identify factors predictive of recurrence and survival rates. In multivariate analysis, age at the time of diagnosis has been shown to correlate with improved survival in large series. ${ }^{32,68}$ Forsyth and coworkers ${ }^{32}$ observed 5 - and 10 -year survival rates of $75 \%$ and $63 \%$, respectively, for younger patients compared with $30 \%$ and $11 \%$ in older patients, respectively. The simple presence of mitoses demonstrated on histopathological examination does not seem to affect survival. ${ }^{32}$ Preliminary observations have linked high proliferative indices to the likelihood of recurrence in patients with intracranial chordomas. ${ }^{60,61}$ Currently, it does not seem that the chondroid variety is associated with an increased rate of survival after adjustment for other factors. ${ }^{32,68}$ The symptom of diplopia has been shown to be associated with increased survival in multivariate analysis. ${ }^{32}$ The possible association between diplopia and increased survival is presently unclear. It is plausible that a diagnosis may be made in patients who present with double vision earlier in the natural history of their disease. ${ }^{32}$ It has also been hypothesized that in patients with chordomas who present with diplopia the lesion may extend more anteriorly rather than growing posteriorly against the brainstem; thus, better prognosis is present in these cases. ${ }^{32}$ Postoperative extraocular motor function is strictly dependent on preoperative function. ${ }^{35,52}$

The importance of the extent of resection on diseasefree and overall survival rates remains debatable. Some authors have even suggested that the apparently dramatic changes in diagnosis and therapy occurring in the past few decades have had minimal or no effect on outcome. ${ }^{104}$ We think that, at least in symptomatic patients, resection, either partial or total, prolongs survival rates, although no study in which authors have systematically analyzed surgery compared with observation alone or biopsy sampling only is available to support this statement. Using current neuroimaging systems (with possibly earlier obtainable diagnoses) and a very aggressive surgical strategy with

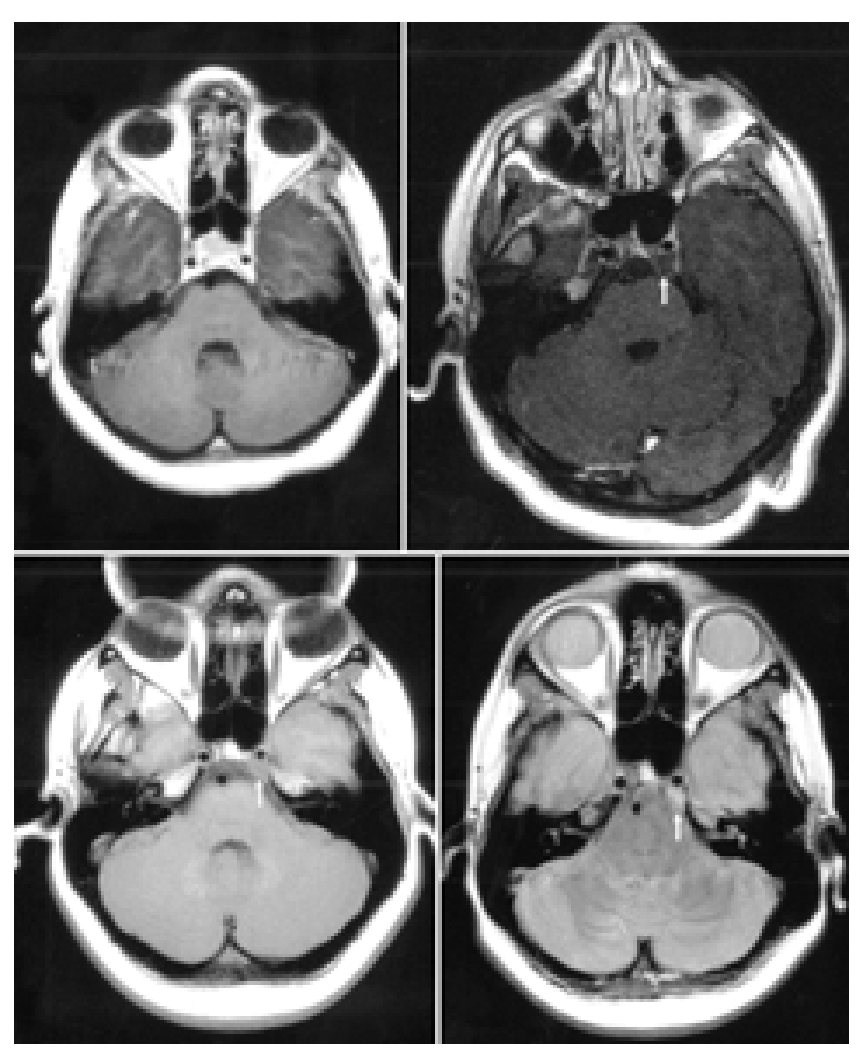

Fig. 5. Magnetic resonance imaging studies obtained in an 11year-old girl who presented with diplopia and a mass involving the clivus in the summer of 1993. In September of that year, an uncomplicated radical resection of the lesion was performed via a transsphenoidal approach. Upper Left: A postoperative image, obtained 6 weeks following her surgery, did not reveal any radiologically visible residual disease. Follow-up study included yearly MR imaging studies. Upper Right: A follow-up image, obtained 2 years later, revealing a small recurrent tumor anterior to the pons on the left side (arrow). The recurrent lesion was treated with gamma knife surgery in 1995. Lower Left: Follow-up image demonstrating no significant changes in the size of the recurrent tumor (arrow), two years after gamma knife surgery. Lower Right: An MR image obtained 7 years after her original surgery and 5 years following gamma knife treatment, demonstrates significant reduction in the size of the treated recurrent tumor (arrow). The girl, now 18 years of age, continues to be asympotomatic and have normal pituitary function and no evidence gamma knife-related side effects. Studies provided courtesy of Drs. L. Steiner and D. Prasad. 
application of complex skull base approaches, Gay and coworkers ${ }^{35}$ reported a 5-year recurrence-free survival rate of $65 \%$. Longer follow-up reviews are required before definitive conclusions can be made regarding the efficacy of such an aggressive strategy. Moreover, as mentioned earlier, possible small incremental benefits must be weighed against the significant complication rate associated with aggressive surgical resection of these lesions. In the experience reported by Gay and coworkers, ${ }^{35} 60 \%$ of patients experienced a transient functional deterioration postoperatively, as assessed by the Karnofsky Performance Scale, and, overall, $40 \%$ of patients were found to suffer a functional decline at follow-up examination. It is possible that younger patients benefit from resection and its extent. ${ }^{32}$

A close follow up with neuroimaging is essential. We suggest obtaining a baseline postoperative study approximately 6 weeks following surgery. If no tumor is visualized, further imaging is recommended at 6-month intervals for the first 1 to 2 years and, in absence of recurrence, yearly thereafter. In case of residual or recurrent disease, strong consideration should be given to undertaking focused radiotherapy. The outlook for patients who present with recurrent disease despite having undergone resection and postoperative radiotherapy is poor. Fagundes, et al., ${ }^{30}$ have reported actuarial 3- and 5-year survival rates of $44 \%$ and $5 \%$, respectively, after local relapse of cranial base and cervical chordomas in patients who have undergone photon-proton radiotherapy. In cases of local recurrence after surgery and radiotherapy, repeated surgery, when feasible, seems to achieve better control than supportive treatment alone. In the aforementioned study by $\mathrm{Fa}-$ gundes, et al., 49 of 60 patients underwent salvage therapy consisting of subtotal resection in most cases (46 of 49 ), whereas the remaining 11 received supportive treatment only. The actuarial 2- and 5-year overall survival rates following relapse for the 49 patients who underwent salvage treatment were $63 \%$ and $6 \%$, respectively, which compared favorably with the 2-year survival rate of $21 \%$ for those receiving supportive therapy only. No correlation was found between survival and age $(<40$ years compared with $>40$ years), tumor volume, or sex once relapse had occurred..$^{30}$

\section{CONCLUSIONS}

Chordomas of the cranial base are a challenging group of tumors. Given their location next to critical structures, it is rarely possible to achieve a true oncological resection. Analysis of large series suggests the existence of two different subgroups of patients with different patterns of disease: one group with aggressive tumors and a high incidence of recurrence within 5 years of treatment, and another group with a much more indolent course and longterm survival. Because cranial base chordomas are relatively uncommon tumors that require long-term follow-up examination, analyses of putative factors predictive of a more aggressive course have largely been inconclusive. It seems, however, that, like many other intracranial tumors, young age at diagnosis is associated with a better prognosis, especially in male patients. We believe that judicious resection followed, in selected patients, by postoperative focused (conformal) high-energy radiotherapy represents the best therapeutic strategy at this point.

\section{References}

1. Al-Mefty O, Borba LAB: Skull base chordomas: a management challenge. J Neurosurg 86:182-189, 1997

2. Amendola BE, Amendola MA, Oliver E, et al: Chordoma: role of radiation therapy. Radiology 158:839-843, 1986

3. Arnold H, Herrmann HD: Skull base chordoma with cavernous sinus involvement. Partial or radical tumour-removal? Acta Neurochir 83:31-37, 1986

4. Austin-Seymour M, Munzenrider J, Goitein M, et al: Fractioned proton radiation therapy of chordoma and low-grade chondrosarcoma of the base of the skull. J Neurosurg 70: 13-17, 1989

5. Austin JP, Urie MM, Cardenosa G, et al: Probable causes of recurrence in patients with chordoma and chondrosarcoma of the base of skull and cervical spine. Int J Radiat Oncol Biol Phys 25:439-444, 1993

6. Bailey P, Bagdasar D: Intracranial chordoblastoma. Am J Pathol 5:439-449, 1929

7. Benk V, Liebsch NJ, Munzenrider JE, et al: Base of skull and cervical spine chordomas in children treated by high-dose irradiation. Int J Radiat Oncol Biol Phys 31:577-581, 1995

8. Berson AM, Castro JR, Petti P, et al: Charged particle irradiation of chordoma and chondrosarcoma of the base of skull and cervical spine: the Lawrence Berkeley Laboratory experience. Int J Radiat Oncol Biol Phys 15:559-565, 1988

9. Borba LAB, Al-Mefty O: Cavernous sinus chordomas, in Eisenberg MB and Al-Mefty O (eds): The Cavernous Sinus: A Comprehensive Text. Philadelphia: Williams \& Wilkins, 2000, pp 321-327

10. Borba LAB, Al-Mefty O, Mrak RE, et al: Cranial chordomas in children and adolescents. J Neurosurg 84:584-591, 1996

11. Bowles AP, Al-Mefty O: The transmaxillary approach to clival chordoma, in Al-Mefty O, Origitano TC, Harkey HL (eds): Controversies in Neurosurgery. New York: Thieme, 1996, pp 113-122

12. Brooks JJ, LiVolsi VA, Trojanowski JQ: Does chondroid chordoma exist? Acta Neurpathol 72:229-235, 1987

13. Brooks JJ, Trojanowski JQ, LiVolsi VA: Chondroid chordoma: a low-grade chondrosarcoma and its differential diagnosis. Curr Top Pathol 80:165-181, 1989

14. Bruner JM, Tien RD: Secondary tumors, in Bigner DD, McLendon RE, Bruner JM (eds): Russel \& Rubinstein's Pathology of Tumors of the Nervous System, ed 6. London: Arnold, Vo 2, 1998, pp 419-450

15. Burger PC, Scheithauer BW: Tumors of the Central Nervous System. Washington, DC: Armed Forces Institute of Pathology, 1994, pp 303-306

16. Campbell WM, McDonald TJ, Unni KK, et al: Nasal and paranasal presentations of chordomas. Laryngoscope 90:612-618, 1980

17. Canalis RF, Martin N, Black K, et al: Lateral approach to tumors of the craniovertebral junction. Laryngoscope 103: 343-349, 1993

18. Catton C, O'Sullivan B, Bell R, et al: Chordoma: long-term follow-up after radical photon irradiation. Radiother Oncol 41: 67-72, 1996

19. Chetiyawardana AD: Chordoma: results of treatment. Clin Radiol 35:159-161, 1984

20. Coffin CM, Swanson PE, Wick MR, et al: Chordoma in childhood and adolescence. A clinicopathologic analysis of 12 cases. Arch Pathol Lab Med 117:927-933, 1993

21. Crockard A: Chordomas and chondrosarcomas of the cranial base: results and follow-up of 60 patients. Neurosurgery 38 420, 1996 (Letter) 
22. Crockard A, Macaulay E, Plowman PN: Stereotactic radiosurgery. VI. Posterior displacement of the brainstem facilitates high dose radiosurgery for clival chordoma. Br J Neurosurg 13:65-70, 1999

23. Crumley RL, Gutin PH: Surgical access for clivus chordoma. The University of California, San Francisco experience. Arch Otolaryngol Head Neck Surg 115:295-300, 1989

24. Cushing H: The Pituitary Body and its Disorders. Philadelphia: JB Lippincott, 1912

25. Debus J, Schulz-Ertner D, Schad L, et al: Stereotactic fractionated radiotherapy for chordomas and chondrosarcomas of the skull base. Int J Radiat Oncol Biol Phys 47:591-596, 2000

26. Delgado TE, Garrido E, Harwick RD: Labiomandibular, transoral approach to chordomas in the clivus and upper cervical spine. Neurosurgery 8:675-679, 1981

27. Derome PJ: Surgical management of tumors invading the skull base. Can J Neurol Sci 12:345-347, 1985

28. Doucet V, Peretti-Viton P, Figarella-Branger D, et al: MRI of intracranial chordomas. Extent of tumor and contrast enhancement: criteria for differential diagnosis. Neuroradiology 39: 571-576, 1997

29. Elias WJ, Chadduck JB, Alden TD, et al: Frameless stereotaxy for transsphenoidal surgery. Neurosurgery 45:271-277, 1999

30. Fagundes MA, Hug EB, Liebsch NJ, et al: Radiation therapy for chordomas of the base of skull and cervical spine: patterns of failure and outcome after relapse. Int J Radiat Oncol Biol Phys 33:579-584, 1995

31. Fischbein NJ, Kaplan MJ, Holliday RA, et al: Recurrence of clival chordoma along the surgical pathway. AJNR 21:578-583, 2000

32. Forsyth PA, Cascino TL, Shaw EG, et al: Intracranial chordomas: a clinicopathological and prognostic study of 51 cases. J Neurosurg 78:741-747, 1993

33. Fraioli B, Esposito V, Santoro A, et al: Transmaxillosphenoidal approach to tumors invading the medial compartment of the cavernous sinus. J Neurosurg 82:63-69, 1995

34. Fuller DB, Bloom JG: Radiotherapy for chordoma. Int J Radiat Oncol Biol Phys 15:331-339, 1988

35. Gay E, Sekhar LN, Rubinstein E, et al: Chordomas and chondrosarcomas of the cranial base: results and follow-up of 60 patients. Neurosurgery 36:887-897, 1995

36. Gay E, Sekhar LN, Wright DC: Chordomas and chondrosarcomas of the cranial base, in Kaye AH, Laws ER Jr (eds): Brain Tumors. An Encyclopedic Approach. Edinburgh: Churchill Livingstone, 1995, pp 777-794

37. Goel A: Chordoma and chondrosarcoma: relationship to the internal carotid artery. Acta Neurochir 133:30-35, 1995

38. Goel A: Middle fossa sub-Gasserian ganglion approach to clivus chordomas. Acta Neurochir 136:212-216, 1995

39. Gutin PH, Leibel SA, Hosobuchi Y, et al: Brachytherapy of recurrent tumors of the skull base and spine with iodine-125 sources. Neurosurgery 20:938-945, 1987

40. Halperin EC: Why is female sex an independent predictor of shortened overall survival after proton/photon radiation therapy for skull base chordomas? Int J Radiat Oncol Biol Phys 38: 225-230, 1997

41. Heffelfinger MJ, Dahlin DC, MacCarty CS, et al: Chordomas and cartilaginous tumors at the skull base. Cancer 32:410-420, 1973

42. Higinbotham NL, Phillips RF, Farr HW, et al: Chordoma. Thirty-five-year study at Memorial Hospital. Cancer 20: 1841-1850, 1967

43. Hug EB, Loredo LN, Slater JD, et al: Proton radiation therapy for chordomas and chondrosarcomas of the skull base. J Neurosurg 91:432-439, 1999

44. Hug EB, Slater JD: Proton radiation therapy for chordomas and chondrosarcomas of the skull base. Neurosurg Clin N Am 11:627-638, 2000

45. Jho HD, Carrau RL, McLaughlin MR, et al: Endoscopic trans- sphenoidal resection of a large chordoma in the posterior fossa. Acta Neurochir 139:343-348, 1997

46. Kendall BE: Cranial chordomas. Br J Radiol 50:687-698, 1977

47. King WA, Becker DP: The transsphenoidal approach to pituitary macroadenomas with cavernous sinus extensions, in AlMefty O, Origitano TC, Harkey HL (eds): Controversies in Neurosurgery. New York: Thieme, 1996, pp 15-20

48. Kondziolka D, Lunsford LD, Flickinger JC: The role of radiosurgery in the management of chordoma and chondrosarcoma of the cranial base. Neurosurgery 29:38-46, 1991

49. Krayenbühl H, Yaşargil MG: Cranial chordomas. Progr Neurol Surg 6:380-434, 1975

50. Kumar PP, Good RR, Skultety FM, et al: Local control of recurrent clival and sacral chordoma after interstitial irradiation with iodine-125: new techniques for treatment of recurrent or unresectable chordomas. Neurosurgery 22:479-483, 1988

51. Lalwani AK, Kaplan MJ, Gutin PH: The transsphenoethmoid approach to the sphenoid sinus and clivus. Neurosurgery 31: 1008-1014, 1992

52. Lanzino G, Sekhar LN, Hirsch WL, et al: Chordomas and chondrosarcomas involving the cavernous sinus: review of surgical treatment and outcome in 31 patients. Surg Neurol 40: 359-371, 1993

53. Larson TC III, Houser OW, Laws ER Jr: Imaging of cranial chordomas. Mayo Clin Proc 62:886-893, 1987

54. Laws E, Thapar K: Parasellar lesions other than pituitary adenomas, in Powell M, Lightman SL (eds): Management of Pituitary Tumors: A Handbook. New York: Churchill-Livingstone, 1996, pp 175-222

55. Laws ER Jr: Clivus chordomas, in Sekhar LN, Janecka IP (eds): Surgery of Cranial Base Tumors. New York: Raven Press, 1993, pp 679-685

56. Laws ER Jr: Cranial chordomas, in Wilkins RH, Rengachary SS (eds): Neurosurgery. New York: McGraw-Hill, 1985, Vol 1, pp. 927-929

57. Laws ER Jr: Transsphenoidal surgery for tumors of the clivus. Otolaryngol Head Neck Surg 92:100-101, 1984

58. Maira G, Pallini R, Anile C, et al: Surgical treatment of clival chordomas: the transsphenoidal approach revisited. J Neurosurg 85:784-792, 1996

59. Matsumoto J, Towbin RB, Ball WS: Cranial chordomas in infancy and childhood. A report of two cases and review of the literature. Pediatr Radiol 20:28-32, 1989

60. Matsuno A, Nagashima T: Radiation therapy for chordomas. J Neurosurg 93:157, 2000 (Letter)

61. Matsuno A, Sasaki T, Nagashima T, et al: Immunohistochemical examination of proliferative potentials and the expression of cell cycle-related proteins of intracranial chordomas. Hum Pathol 28:714-719, 1997

62. McDermott MW, Gutin PH: Image-guided surgery for skull base neoplasms using the ISG viewing wand. Anatomic and technical considerations. Neurosurg Clin N Am 7:285-295, 1996

63. Meis JM, Giraldo AA: Chordoma. An immunohistochemical study of 20 cases. Arch Pathol Lab Med 112:553-556, 1988

64. Menezes AH, Gantz BJ, Traynelis VC, et al: Cranial base chordomas. Clin Neurosurg 44:491-509, 1997

65. Meyers SP, Hirsch WL, Curtin HD, et al: Chordomas of the skull base: MR features. AJNR 13:1627-1636, 1992

66. Mierau GW, Weeks DA: Chondroid chordoma. Ultrastruct Pathol 11:731-737, 1987

67. Miettinen M: Chordoma. Antibodies to epithelial membrane antigen and carcinoembryonic antigen in differential diagnosis. Arch Pathol Lab Med 108:891-892, 1984

68. Mitchell A, Scheithauer BW, Unni KK, et al: Chordoma and chondroid neoplasms of the spheno-occiput. An immunohistochemical study of 41 cases with prognostic and nosologic implications. Cancer 72:2943-2949, 1993

69. Muthukumar N, Kondziolka D, Lunsford LD, et al: Stereotactic 
radiosurgery for chordoma and chondrosarcoma: further experiences. Int J Radiat Oncol Biol Phys 41:387-392, 1998

70. Nishigaya K, Kaneko M, Ohashi Y, et al: Intradural retroclival chordoma without bone involvement: no tumor regrowth 5 years after operation. Case report. J Neurosurg 88:764-768, 1998

71. Nolte K: Malignant intracranial chordoma and sarcoma of the clivus in infancy. Pediatr Radiol 8:1-6, 1979

72. O'Connell JX, Renard LG, Liebsch NJ, et al: Base of skull chordoma. A correlative study of histologic and clinical features of 62 cases. Cancer 74:2261-2267, 1994

73. O'Neill P, Bell BA, Miller JD, et al: Fifty years of experience with chordomas in southeast Scotland. Neurosurgery 16: 166-170, 1985

74. Pearlman AW, Friedman M: Radical radiation therapy of chordoma. Am J Roentgenol Radium Ther Nucl Med 108: 333-341, 1970

75. Perzin KH, Pushparaj N: Nonepithelial tumors of the nasal cavity, paranasal sinuses, and nasopharynx. A clinicopathologic study. XIV: Chordomas. Cancer 57:784-796, 1986

76. Rabadán A, Conesa H: Transmaxillary-transnasal approach to the anterior clivus: a microsurgical anatomical model. Neurosurgery 30:473-482, 1992

77. Raffel C, Wright DC, Gutin PH, et al: Cranial chordomas: clinical presentation and results of operative and radiation therapy in twenty-six patients. Neurosurgery 17:703-710, 1985

78. Raju T, Adelman LS, Dahl D, et al: Localization of keratin in the nothochord and in notochord derived tumors-immunological study of rat embryo and human chordoma. Int J Devl Neuroscience 1:375-382, 1983

79. Rich TA, Schiller A, Suit HD, et al: Clinical and pathologic review of 48 cases of chordoma. Cancer 56:182-187, 1985

80. Richter HJ Jr, Batsakis JG, Boles R: Chordomas: nasopharyngeal presentation and atypical long survival. Ann Otol Rhinol Laryngol 84:327-332, 1975

81. Rosenberg AE, Nielsen GP, Keel SB, et al: Chondrosarcoma of the base of the skull: a clinicopathologic study of 200 cases with emphasis on its distinction from chordoma. Am J Surg Pathol 23:1370-1378, 1999

82. Santoni R, Liebsch N, Finkelstein DM, et al: Temporal lobe (TL) damage following surgery and high-dose photon and proton irradiation in 96 patients affected by chordomas and chondrosarcomas of the base of the skull. Int J Radiat Oncol Biol Phys 41:59-68, 1998

83. Schul C, Wassmann H, Skopp GB, et al: Surgical management of intraosseous skull base tumors with aid of Operating Arm System. Comput Aided Surg 3:312-319, 1998

84. Scimeca PG, James-Herry AG, Black KS, et al: Chemotherapeutic treatment of malignant chordoma in children. J Pediatr Hematol Oncol 18:237-240, 1996

85. Seifert V, Laszig R: Transoral transpalatal removal of a giant premesencephalic clivus chordoma. Acta Neurochir 112: 141-146, 1991

86. Sekhar LN, Nanda A, Sen CN, et al: The extended frontal approach to tumors of the anterior, middle, and posterior skull base. J Neurosurg 76:198-206, 1992

87. Sen CN: The subtemporal and preauricular infratemporal approach to clival chordomas and chondrosarcomas, in Al-Mefty O, Origitano TC, Harkey HL (eds): Controversies in Neurosurgery. New York: Thieme, 1996, pp 122-125

88. Sen CN, Sekhar LN: An extreme lateral approach to intradural lesions of the cervical spine and foramen magnum. Neurosurgery 27:197-204, 1990

89. Sen CN, Sekhar LN, Schramm VL, et al: Chordoma and chondrosarcoma of the cranial base: an 8-year experience. Neurosurgery 25:931-941, 1989
90. Sibley RK, Day DL, Dehner LP, et al: Metastasizing chordoma in early childhood: a pathological and immunohistochemical study with review of the literature. Pediatr Pathol 7:287-301, 1987

91. Steiner L, Payne BR, Prasad D, et al: Gamma surgery in cerebral vascular lesions, malformations, tumors, and functional disorders, in Schmidek HH (ed): Schmidek \& Sweet Operative Neurosurgical Techniques, ed 4. Philadelphia: WB Saunders, 2000, pp

92. Suit HD, Goitein M, Munzenrider J, et al: Definitive radiation therapy for chordoma and chondrosarcoma of base of skull and cervical spine. J Neurosurg 56:377-385, 1982

93. Tai PT, Craighead P, Bagdon F: Optimization of radiotherapy for patients with cranial chordoma. A review of dose-response ratios for photon techniques. Cancer 75:749-756, 1995

94. Tedeschi H, Rhoton AL: Lateral approaches to the petroclival region. Surg Neurol 41:180-216, 1994

95. Terahara A, Niemierko A, Goitein M, et al: Analysis of the relationship between tumor dose inhomogeneity and local control in patients with skull base chordoma. Int J Radiat Oncol Biol Phys 45:351-358, 1999

96. Thodou E, Kontogeorgos G, Scheithauer BW, et al: Intrasellar chordomas mimicking pituitary adenoma. J Neurosurg 92: 976-982, 2000

97. Toda H, Kondo A, Iwasaki K: Neuroradiological characteristics of ecchordosis physaliphora. Case report and review of the literature. J Neurosurg 89:830-834, 1998

98. Tomlison FH, Scheithauer BW, Forsythe PA, et al: Sarcomatous transformation in cranial chordoma. Neurosurgery 31: 13-18, 1992

99. Valderrama E, Kahn LB, Lipper S, et al: Chondroid chordoma. Electron-microscopic study of two cases. Am J Surg Pathol 7:625-632, 1983

100. Volpe NJ, Liebsch NJ, Muzenrider JE, et al: Neuro-ophthalmologic findings in chordoma and chondrosarcoma of the skull base. Am J Ophthalmol 115:97-104, 1993

101. Volpe R, Mazabraud A: A clinicopathologic review of 25 cases of chordoma (a pleomorphic and metastasizing neoplasm). Am J Surg Pathol 7:161-170, 1983

102. Yaşargil MG: Microneurosurgery of CNS Tumors. New York: Thieme, 1996, Vol IVB, pp 186-191

103. Walker WP, Landas SK, Bromley CM, et al: Immunohistochemical distinction of classic and chondroid chordomas. Modern Pathol 4:661-666, 1991

104. Watkins L, Khudados ES, Kaleoglu M, et al: Skull base chordomas: a review of 38 patients, 1958-88. Br J Neurosurg 7: 241-248, 1993

105. Wojno KJ, Hruban RH, Garin-Chesa P, et al: Chondroid chordomas and low-grade chondrosarcomas of the craniospinal axis. An immunohistochemical analysis of 17 cases. Am J Surg Pathol 16:1144-1152, 1992

106. Wold LE, Laws ER Jr: Cranial chordomas in children and young adults. J Neurosurg 59:1043-1047, 1983

107. Wolfe JT III, Scheithauer BW: "Intradural chordoma" or "giant ecchordosis physaliphora"? Report of two cases. Clin Neuropathol 6:98-103, 1987

108. Wright D: Nasopharyngeal and cervical chordoma-some aspects of their development and treatment. J Laryngol Otol 81: 1337-1355, 1967

Manuscript received January 18, 2001.

Accepted in final form March 5, 2001.

Address reprint requests to: Giuseppe Lanzino, M.D., Department of Neurosurgery, Box 800212 University of Virginia Health Sciences Center, Charlottesville, Virginia 22908. email: glanzino@ hotmail.com. 